\title{
Osteoporosis is a neglected health priority in Arab World: a comparative bibliometric analysis
}

\author{
Waleed M Sweileh ${ }^{1 *}$, Samah W Al-Jabi ${ }^{2}$, Sa'ed H Zyoud ${ }^{2}$, Ansam F Sawalha ${ }^{1}$ and Mustafa A Ghanim ${ }^{3}$
}

\begin{abstract}
Osteoporosis is an important health problem with serious consequences. Evaluation of osteoporosis scientific output from Arab countries has not been explored and there are few internationally published reports on research activity about osteoporosis. The main objectives of this study were to analyze the research output originating from Arab countries and 3 Middle Eastern non-Arab countries, particularly Israel, Turkey and Iran in the field of osteoporosis. Original scientific articles or reviews published from the 21 Arab countries, Israel, Turkey and Iran about "Osteoporosis" were screened using the ISI Web of Science database. The time frame for the result was up to year 2012. The total number of original and review research articles published globally about osteoporosis was 43,571 . The leading country in osteoporosis research was United States of America (14,734; 33.82\%). Worldwide, Turkey ranked 16th while Israel and Iran ranked 24th and 31st respectively. Among Arab countries, Egypt and Kingdom of Saudi Arabia came on positions 41 and 45 respectively. A total of 426 documents about "osteoporosis" were published from Arab countries which represents $0.98 \%$ of the global research output. Research about osteoporosis from Arab countries was very low until 2002 and then increased steadily. The total number of citations for osteoporosis documents from the Arab world was 5551 with an average citation of 13.03 per document and an $h$ - index of 35. Thirty (7.04\%) documents published from Arab countries about osteoporosis were published in Saudi Medical Journal. Egypt, with a total publication of 117 (27.47\%) ranked first among the Arab countries in research about osteoporosis while American University in Beirut was the most productive institution with a total of 47 (11.03\%) documents. Compared with other non-Arab countries in the Middle East, the research productivity from the Arab countries was lesser than that from Turkey and Israel but higher than that from Iran. The present data showed low research productivity in osteoporosis field in Arab countries. Research output can be improved by investing in more international and national collaborative research projects in the field of osteoporosis.
\end{abstract}

Keywords: Osteoporosis; Arab countries; Bibliometric; ISI; Web of Science

\section{Background}

Osteoporosis is defined as a disease characterized by low bone mass and micro architectural deterioration of bone tissue, enhanced bone fragility and an increase in fracture risk (Kanis 1994; NIH Consensus Development Panel on Osteoporosis Prevention 2001). Unfortunately, the 2010 World Health Organization (WHO) Global Status report have discussed in detail the increased mortality and morbidity of many non-communicable diseases like cardiovascular, cancer and diabetes but osteoporosis was not mentioned in the report (WHO 2011). Approximately

\footnotetext{
* Correspondence: waleedsweileh@yahoo.com

${ }^{1}$ Department of Pharmacology/Toxicology, College of Medicine and Health Sciences, An-Najah National University, Nablus, Palestine

Full list of author information is available at the end of the article
}

1.6 million hip fractures occur worldwide each year and this number could triple or quadruple and reach between 4.5 and 6.3 million by the year 2050 which make osteoporosis a global disease (Roux et al. 2012). In Middle East, the problem of osteoporosis will soon be of greater importance considering the steady growth of the ageing population ((Maalouf et al. 2007); IOF 2011a, 2012). Iran accounts for $0.85 \%$ of the global burden of hip fractures and $12.4 \%$ of the burden of hip fractures in the Middle East (Soveid et al. 2005; Moayyeri et al. 2006; Ahmadi-Abhari et al. 2007; Beyranvand \& Mohammadi 2009; Shahnazari et al. 2013). Furthermore, hypovitaminosis D is highly prevalent in Middle Eastern countries and might be a strong contributing factor for osteoporosis (Gannage-Yared et al. 2000).

\section{实}


The Middle East and Africa Audit about epidemiology, cost and burden of osteoporosis was published in 2011 by the International Osteoporosis Foundation (IOF). The audit focused on 17 countries including 11 Arab countries in the Middle East, Turkey, Iran and few other countries in Africa. According to the executive summary of the IOF audit report, osteoporosis is a neglected disease, not being integrated in medical curricula of most countries, and the level of awareness about osteoporosis is estimated as poor to medium in most studied countries (IOF 2011b). Furthermore, the audit stated that osteoporosis is not identified as a priority in most countries and that access to Dual-energy X-ray absorptiometry (DEXA) machines to measure bone mineral density is extremely limited. A primary recommendation of the IOF report is the need for more research to gather the necessary evidence that would aid health authorities to develop comprehensive healthcare policies at all levels for osteoporosis.

Bibliometrics refers to the implementation of statistical methods for evaluating the research productivity, for individuals, institutes and countries. Bibliometric analysis is a useful tool to obtain information about the current state of research in particular areas and allows researchers to identify new lines of research (Smith 2008; Smith 2012). Bibliometrics has been applied to various diseases and is now widely accepted as a method of measuring research and literacy output in any particular area ((Huber \& Gullion 2003; Hofman et al. 2006; Smith 2010b; Smith 2010a; Rashidi et al. 2013; Bramness et al. 2014); Zyoud et al. 2014b; (Zyoud et al. 2014e)). Furthermore, the results of bibliometric analysis might help health policy makers and people in academia to shape up and direct research in the next decade. Bibliometrics of published research about osteoporosis from Arab countries has not been investigated before. Therefore, we conducted this study to analyze the quantity and quality of osteoporosis - based research productivity from Arab countries and compare it with that from non-Arab countries, particularly Turkey and Iran.

\section{Methods}

The data used in this study were based on the ISI Web of Science, which is one of the world largest databases of peer-reviewed literature. The world-leading citation databases provide authoritative, multidisciplinary coverage from more than 12,000 high impact research journals worldwide (Thomson Reuters 2013). All Arab countries: Kingdom of Saudi Arabia (KSA); Egypt; Jordan; Lebanon; Qatar; Bahrain; Kuwait; Morocco; Tunisia; Syrian Arab Republic (SAR); United Arab Emirates (UAE); Iraq; Sudan; Yemen; Algeria; Comoros; Djibouti; Libya; Mauritania; Oman; Somalia, except Palestine, were used as country keys followed by "osteoporosis" key word as a search topic. Palestine was excluded from search keys because the Web of Science database does not recognize Palestine as an independent state yet. Because we are interested in osteoporosis and no other related terms, the key word used was restricted to osteoporosis. Furthermore, to increase the accuracy of results, research was refined and limited to original research articles and review articles because they represent the research activities, while other types of documents like editorials, conference proceedings, and others were excluded. The time frame for the result was up to year 2012. The 2013 and 2014 years were excluded because they are still open for new journal issues.

The database then generates a count of the total number of original articles, the total citations, and the value of the $h$-index (highly cited index). The $h$-index represents the number of citations received for each of the documents in descending order, while the $h$-graph measures the impact of a set of documents and displays the number of citations per document (for example: $h$-index of 10 means that there are 10 items that have 10 citations or more). The $h$-index was originally developed as a measure of qualifying research performance (Baldock et al. 2009; Schreiber 2013). Scientific output was evaluated based on a methodology developed and used in other bibliometric studies ((Sweileh et al. 2014b); Sweileh et al. 2014c; Zyoud et al. 2014b; Zyoud et al. 2014d; (Zyoud et al. 2014e)). The collected data were used to generate the following information: (a) total and trends of contributions to research about osteoporosis during all previous years up to December 31, 2012; (b) Arab countries research productivity and collaboration patterns; (c) journals in which Arab world researchers published; and (d) the citations received by the publications.

\section{Ethical approval}

The Institutional Review Board (IRB) at An-Najah National University does not require submission of an IRB application for such study. The IRB considered that there is no risk for human subjects in such publications since the data are based on published literature and did not involve any interactions with human subjects.

\section{Statistical analysis}

Data from ISI Web of Science were exported to Microsoft Office Excel ${ }^{\circ}$ and then transferred to the Statistical Package for Social Sciences (SPSS; SPSS Inc., Chicago, IL, USA) program version 15 for analysis. The measurements of bibliometric analysis (e.g. countries, cited articles, institutions) were converted to the rank order using the standard competition ranking (SCR) (Zyoud et al. 2014c). We took into consideration the top 10 ranking in each item. If the measurements of bibliometric analysis have the same ranking number, then a gap is left in 
the following ranking numbers. The journal's impact factors (IF) were evaluated using the Journal Citation Report (JCR; Web of Knowledge) 2012 science edition by Thomson Reuters (New York, NY, USA).

\section{Results}

The total number of documents retrieved from ISI Web of Science using the methodology stated and without specifying the name of any country was 43,571 . This number represents the global research productivity (original research articles and reviews) in osteoporosis as a research topic up to year 2012. Global research productivity in osteoporosis was much less than for hypertension (202,838 documents) and that for diabetes mellitus (126,187 documents). The leading countries in osteoporosis research were United States of America (USA) (14,734; 33.82\%) followed by England (3,862; 8.86\%) and Japan (3012; 6.91\%). Worldwide, Turkey ranked 16th while Israel and Iran ranked 24th and 31 respectively. Among Arab countries, Egypt and KSA came on positions 41 and 45 respectively. At the global level, 40,811 (93.66\%) of osteoporosis documents were written in English. The remaining documents were published by 24 different languages, mainly German (1,286; 2.95\%) and French (634; 1.45\%) languages. The annual global research productivity about osteoporosis remained low and steady until early 1990, after which, a steady and sharp increase in osteoporosis research was observed globally. The first article about osteoporosis was published in 1913 in by Conlon, FA at Boston Medical and Surgical Journal. The main research area of osteoporosis documents published globally was Endocrinology/ Metabolism (12754; 29.27\%) followed by General/ Internal medicine (4,431; 10.17\%). The journals in which most documents about osteoporosis were published include Osteoporosis International (2,685; 6.16\%) followed by Journal of Bone and Mineral Research (1940; 4.45\%) and Bone (1802; 4.14\%). Approximately 5\% $(2,158)$ of global osteoporosis documents were open access. The most productive institutions of osteoporosis research were University of California at San Francisco (USA), Harvard University (USA), and University of Sheffield (UK) with a total of $948(2.18 \%)$, 804 (1.85\%) and 525 (1.20\%) documents respectively.

When the same methodology was applied using the list of the 21 Arab countries, 426 documents were retrieved. Therefore, research about osteoporosis that was published from Arab countries represents approximately $0.98 \%$ of the global research productivity related to osteoporosis. Of the 426 documents, 412 (96.71\%) were written in English language while 13 (3.05\%) documents were published in French language and one document (0.24\%) was published in German language. Sixty four osteoporosis documents (15.02\%) published from the Arab world were open access while the remaining (362; 84.98\%) were not open access. The annual number of documents published from Arab countries indicated that research activity about osteoporosis remained low until 2002 and showed a steady and double increase after 2003 (Figure 1). More than one third $(41.78 \%)$ of documents about osteoporosis from the Arab world were published in 2010, 2011 and 2012 (Figure 1). When retrieved data was analyzed based on country production, Egypt $(117 ; 27.46 \%)$ had the highest research output followed by Kingdom of Saudi Arabia (KSA) $(97 ; 22.77 \%)$ and Lebanon (76; 17.84\%). More than two thirds $(290 ; 68.08 \%)$ of osteoporosis research from Arab world came from three Arab countries, particularly Egypt, KSA and Lebanon. No data related to osteoporosis was found from Somalia, Djibouti, Mauritania and Comoros (Table 1). The first article about osteoporosis co-authored by an Arab researcher/institution was published in 1983 (Sakati \& Nyhan 1983). Endocrinology/ Metabolism (96; 22.53\%) was the main research area of the 426 published osteoporosis documents followed by General/Internal medicine $(68 ; 15.96 \%)$ and Rheumatology (42; 9.86\%). Top 10 research areas of osteoporosis documents from Arab countries are shown in Table 2. More than half (226; 53.05\%) of the 426 published osteoporosis documents from the Arab countries were related to females/women. Collaboration between Arab countries and non-Arab countries in osteoporosis research and publication was evident. Countries whose researchers collaborated most with investigators in the Arab world include the USA; $(51 ; 11.97 \%)$ followed by France $(28 ; 6.57 \%)$ and Canada $(19 ; 4.46 \%)$.

Table 3 lists the top 10 journals in which documents about osteoporosis were published from Arab countries. Thirty (7.04\%) documents about osteoporosis published from Arab countries appeared in Saudi Medical Journal which is a medical journal with wide medical scope based in KSA. Of the top 10 journals, 6 were in the specific field of bone and rheumatology, 3 had general medical scope, one was in the field of women's health, and none has an impact factor above 5. Furthermore, 2 journals were based and published from KSA. Interest of Saudi researchers in osteoporosis research is evident in top 10 Arabic institutions involved in osteoporosis research (Table 4). Three of the top 10 productive institutions were based in KSA while 4 were based in Egypt. Of interest, the top productive institution was American University in Beirut (47; 11.03\%). Seven institutions in the top 10 list are academic institutions, 2 are hospitals and 1 is a national research centre in Egypt.

The total number of citations for osteoporosis documents from the Arab world, at the time of data analysis (March 28, 2014), was 5551 with an average citation of 13.03 per document. The total number of citations excluding self-citation was 5019 . Of the 426 documents considered for the $h$-index, 35 had been cited at least 35 


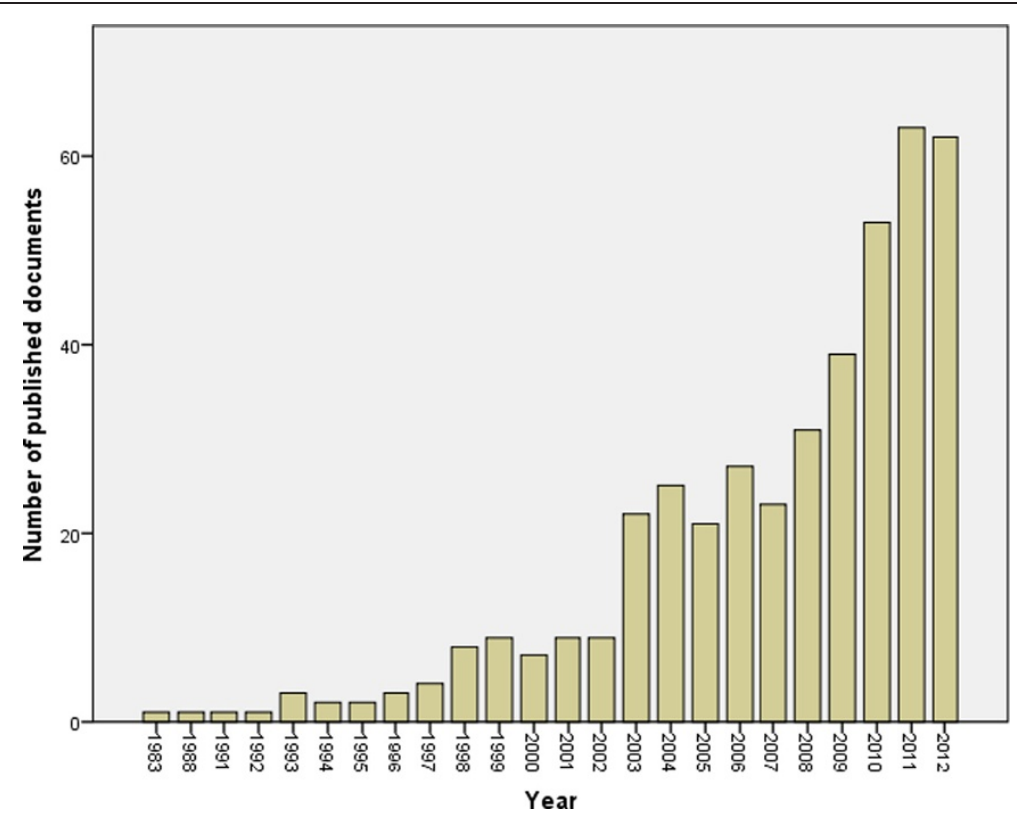

Figure 1 Growth of osteoporosis research in Arab countries as extracted from ISA web of science using osteoporosis as a key topic search.

Table 1 Contribution of each Arab country to the 426 published documents about osteoporosis

\begin{tabular}{|c|c|}
\hline Country & $\begin{array}{l}\text { Number of documents } \\
\qquad \mathrm{N}=426(\%)^{*}\end{array}$ \\
\hline Egypt & $117(27.47)$ \\
\hline Kingdom of Saudi Arabia & $97(22.77)$ \\
\hline Lebanon & $76(17.84)$ \\
\hline Morocco & $51(11.97)$ \\
\hline Kuwait & $28(6.57)$ \\
\hline Tunisia & $22(5.16)$ \\
\hline Jordan & $16(3.76)$ \\
\hline United Arab Emirates & $11(2.58)$ \\
\hline Oman & $9(2.11)$ \\
\hline Qatar & $8(1.88)$ \\
\hline Libya & $4(0.94)$ \\
\hline Iraq & $2(0.47)$ \\
\hline Sudan & $2(0.47)$ \\
\hline Algeria & $1(0.24)$ \\
\hline Bahrain & $1(0.24)$ \\
\hline Syria & $1(0.24)$ \\
\hline Yemen & 0 \\
\hline Somalia & 0 \\
\hline Comoros & 0 \\
\hline Djibouti & 0 \\
\hline Mauritania & 0 \\
\hline
\end{tabular}

*Total exceeds $100 \%$ because of overlap in some documents among more than one Arab country. times at the time of data analysis. Compared with other non-Arab countries in the Middle East, the research productivity from the Arab countries was lesser than that from Turkey (number of documents $=873$; total citations $=7467$; number of citations per document $=8.55$; $\mathrm{h}$ index $=33$ ) and Israel (number of documents $=486$; total citations $=16591$; number of citations per document $=34.14$; $\mathrm{h}$ index $=57$ ) but higher than that from Iran (number of documents $=185$; total citations $=1471$; number of citations per document $=7.95$; $\mathrm{h}$ index $=17$ ). Number of documents and citation analysis of osteoporosis documents published from Arab countries, Turkey, Israel and Iran is shown in Table 5.

Table 2 Research areas of the $\mathbf{4 2 6}$ documents about osteoporosis published from the 21 Arab countries

\begin{tabular}{lccc}
\hline $\mathbf{S C R}^{\mathbf{a}}$ & Research area & $\mathbf{N}=\mathbf{4 2 6}$ & \% \\
\hline 1st & Endocrinology Metabolism & 96 & 22.54 \\
2nd & General Internal Medicine & 68 & 15.96 \\
3rd & Rheumatology & 42 & 9.86 \\
4th & Obstetrics Gynecology & 23 & 5.40 \\
5th & Pharmacology Pharmacy & 19 & 4.46 \\
6th & Orthopedics & 17 & 3.99 \\
7th & Geriatrics Gerontology & 14 & 3.29 \\
7th & Research Experimental Medicine & 14 & 3.29 \\
9th & Genetics Heredity & 13 & 3.05 \\
9th & Public Environmental Occupational Health & 13 & 3.05 \\
\hline
\end{tabular}

Abbreviations: SCR Standard Competition Ranking.

${ }^{\mathrm{a}}$ Equal research areas have the same ranking number and then a gap is left in the ranking numbers. 
Table 3 Top 10 journals in which documents about osteoporosis were published from the 21 Arab countries

\begin{tabular}{lccc}
\hline SCR & Journal & $\begin{array}{c}\text { Number of documents } \\
\mathbf{N}=\mathbf{4 2 6}(\mathbf{1 0 0 \% )}\end{array}$ & $\mathbf{~ I F ~}^{\mathbf{a}}$ \\
\hline 1st & Saudi Medical Journal & $30(7.04)$ & 0.619 \\
2nd & Journal of Clinical Densitometry & $26(6.10)$ & 1.713 \\
3rd & Osteoporosis International & $17(3.99)$ & 4.039 \\
4th & Bone & $16(3.76)$ & 3.823 \\
5th & Annals of Saudi Medicine & $14(3.29)$ & 1.123 \\
6th & Clinical Rheumatology & $12(2.82)$ & 2.037 \\
7th & Rheumatology International & $10(2.35)$ & 2.214 \\
8th & $\quad$ Maturitas & $9(2.11)$ & 2.844 \\
9th & Archives of Medical Science & $7(1.64)$ & 1.067 \\
10th & Journal of Bone and Mineral & $6(1.41)$ & 2.219 \\
& Metabolism & & \\
\hline
\end{tabular}

Abbreviations: SCR Standard Competition Ranking, IF impact factor. ${ }^{a}$ The impact factor was reported according to Institute for Scientific Information (ISI) journal citation reports (JCR) 2012.

\section{Discussion}

Reducing osteoporosis related morbidity and mortality in Arab countries requires an understanding of how these various countries progress in osteoporosis scientific research. Such understanding is instrumental for the development of an effective plan for this disease. Identifying research output and research activity in this field is of great importance to public health in general and women's health in particular. Cultural and educational barriers make women in Arab countries more vulnerable to osteoporosis. One mechanism in overcoming

Table 4 Top 10 active institutions in osteoporosis research from Arab countries

\begin{tabular}{cccc}
\hline SCR $^{\text {a }}$ & Institute & $\begin{array}{c}\text { Number } \\
\text { N= 426 (\%) }\end{array}$ & Affiliation \\
\hline 1st & American University Beirut & $47(11.03)$ & Lebanon \\
2nd & King Saud University & $30(7.04)$ & KSA \\
3rd & Cairo University & $28(6.57)$ & Egypt \\
4th & Mil Hospital Mohammed V & $27(6.34)$ & Morocco \\
5th & Kuwait University & $24(5.63)$ & Kuwait \\
5th & National Research Center & $24(5.63)$ & Egypt \\
7th & Ain Shams University & $17(3.99)$ & Egypt \\
8th & King Faisal Specialist Hospital & $15(3.52)$ & KSA \\
& Research Centre & & \\
9th & Mansoura University & $12(2.82)$ & Egypt \\
10th & King Fahd University Hospital & $11(2.58)$ & KSA \\
10th & Saint Joseph University & $11(2.58)$ & Lebanon \\
\hline
\end{tabular}

Abbreviations: $\mathrm{SCR}=$ Standard Competition Ranking; $\mathrm{KSA}=$ Kingdom of Saudi Arabia.

${ }^{a}$ Equal institutions have the same ranking number, and then a gap is left in the ranking numbers. such barriers is to shed more light on quantity and quality of osteoporosis research in the Arab world.

Our study was limited to 426 documents extracted from ISI web of Science, and, therefore, cannot be generalized to the osteoporosis literature covered by other databases such as Scopus and Google Scholar. However, the study does give a clear picture about the characteristics of published osteoporosis documents from Arab countries compared with that from Turkey, Israel and Iran. Although the quality and quantity of research in a particular area might differ from one search engine to another, ISI search engine remains one of the best official available tools for analyzing and tracking citations, and comparing citations among different research groups and different institutions. To the best of authors' knowledge, this is the first article to analyze and compare the quantity and quality of osteoporosis-based research from Arab and non-Arab countries. Research indicators showed that research output particularly from Arab countries and Iran in the field of osteoporosis was low. Assessing the quality of research output is not an easy task. However, it was interesting to assess the quality of osteoporosis research in these countries as measured by the $h$-index. Unfortunately, the $h$-index for osteoporosis research output from Arab countries and Iran was also low. This was not surprising given that publishing high quality research requires significant effort, funding, and collaboration with international scientists which seem lacking in the field of osteoporosis research. This is of great importance since high quality publications allow established researchers to be able to obtain further funding and for young researchers to be more competitive in career advancement (Dawson 2013). Our results indicated that more effort is needed to bridge the gap in osteoporosis-based research from Arab and non-Arab countries compared with developed countries. Furthermore, osteoporosis needs to be given priority similar to other non-communicable diseases like diabetes mellitus and hypertension.

Results showed that the majority of top 10 institutions in osteoporosis research were universities with medical schools that were successful in making their contributions visible through ISI-indexed journals. This may be attributed to the emphasis by universities for academic staff to publish in indexed journals with high impact factor. Research productivity reveals intellectual output by the institution and is useful to university administrators when evaluating performance of university faculties in the light of university ranking among various universities (Zainal \& Zainab 2011; Sweileh et al. 2014e).

To the best of our knowledge, this study is the first of its kind to obtain initial data regarding the publication and citation productivity of Arab and non-Arab countries in the Middle East in the field of osteoporosis in 
Table 5 Osteoporosis research output from Arab countries compared with that from Turkey, Israel and Iran

\begin{tabular}{lcccc}
\hline Data/Country & $\begin{array}{c}\text { 21 Arab } \\
\text { countries }\end{array}$ & Turkey & Israel & Iran \\
\hline Number of population in millions & 500 & 60 & 8 & 80 \\
$\begin{array}{l}\text { Number of published research } \\
\text { articles and review articles }\end{array}$ & 426 & 873 & 486 & 185 \\
Total number of citations & 5551 & 7467 & 16591 & 1471 \\
Average citation per document & 13.03 & 8.55 & 34.14 & 7.95 \\
h-index & 35 & 33 & 57 & 17 \\
\hline
\end{tabular}

the ISI database. Few articles were published about osteoporosis bibliometrics. One study was recently published from India and came to similar conclusions to our findings and another study was published from China 2 decades ago (Wei 1995; (Bhardwaj \& Ram 2013)). Internationally, several articles have been published about bibliometrics in rheumatology; however none was published about bibliometrics of osteoporosis (Maese Manzano 2009; Cheng \& Zhang 2013). Rheumatology bibliometric studies have also pointed that some research field in rheumatology like arthritis is lagging behind (Glazier et al. 2001). The main goal of our study is to direct attention and to open doors for a scientific discussion among professionals and academics about osteoporosis research. Academic institutions in the Arab world are advised to initiate osteoporosis research and to strengthen research collaboration with international researchers and institutions in which osteoporosis research has evolved. For future studies in this direction, it is recommended that similar quantitative and qualitative research analyses for other disciplines, based on the same methodology, should be carried out. Our study is not without limitations, most of which are the same as those of studies performed in other biomedical fields ((Sweileh et al. 2014a; Sweileh et al. 2014d), b; (Zyoud et al. 2014a; Zyoud et al. 2014f)). First of all, articles published in non-ISI journals were not included, although they might contribute to scientific productivity. Another limitation is that some international journals do not recognize countries like Palestine as a separate country and publications from Palestine may be affiliated with Israel as a country. Therefore, some publications from Palestine might have been missed from our analysis. Finally, it should be noted that research output for certain institutions could have been under-estimated because of writing their English names differently in different articles. Therefore, such authors might have 2 or more institute profiles in ISI Web of Science database because their names were written differently in different articles.

\section{Conclusions}

The present data showed that Arab countries have relatively low research productivity in the field of osteoporosis. Research output can be improved by investing in more international and national collaborative research projects in the field of osteoporosis.

\section{Abbreviations \\ SPSS: Statistical Package for Social Sciences; ISI: Institute for Scientific Information; KSA: Kingdom of Saudi Arabia; UAE: United Arab Emirates; SAR: Syrian Arab Republic; USA: United States of America; WHO: World Health Organization; JCR: Journal Citation Report; IRB: Institutional Review Board; IOF: International Osteoporosis Foundation; SCR: Standard Competition Ranking; IFs: impact factors; DEXA: Dual-energy X-ray absorptiometry.}

\section{Competing interests}

The authors declare that they have no competing interests.

\section{Authors' contributions}

All authors were involved in drafting the article, and all authors approved the final version to be submitted for publication. WS and SZ contributed to idea and design while SA, AS and MG contributed to data analysis, critical thinking and manuscript writing and submission.

\section{Author details}

'Department of Pharmacology/Toxicology, College of Medicine and Health Sciences, An-Najah National University, Nablus, Palestine. ${ }^{2}$ Department of Clinical and Community Pharmacy, College of Medicine and Health Sciences, An-Najah National University, Nablus, Palestine. ${ }^{3}$ Department of Biochemistry and Genetics, College of Medicine and Health Sciences, An-Najah National University, Nablus, Palestine.

Received: 26 May 2014 Accepted: 6 August 2014

Published: 12 August 2014

\section{References}

Ahmadi-Abhari S, Moayyeri A, Abolhassani F (2007) Burden of hip fracture in Iran. Calcif Tissue Int 80(3):147-153, doi:10.1007/s00223-006-0242-9

Baldock C, Ma R, Orton CG (2009) The $h$ index is the best measure of a scientist's research productivity. Med Phys 36:1043, http://dx.doi.org/10.1118/1.3089421

Beyranvand M, Mohammadi G (2009) Incidence of hip fracture in Kermanshah, Iran. Arch Osteoporos 4(1-2):67-70, doi:10.1007/s11657-009-0030-z

Bhardwaj RK, Ram S (2013) Mapping of Indian research output on osteoporosis. Ann Libr Inf Stud 60(4):276-283

Bramness JG, Henriksen B, Person O, Mann K (2014) A Bibliometric Analysis of European versus USA Research in the Field of Addiction. Research on Alcohol, Narcotics, Prescription Drug Abuse, Tobacco and Steroids 20012011. Eur Addict Res 20(1):16-22, doi:10.1159/000348260

Cheng T, Zhang G (2013) Worldwide research productivity in the field of rheumatology from 1996 to 2010: a bibliometric analysis. Rheumatology (Oxford) 52(9):1630-1634, doi:10.1093/rheumatology/ket008

Dawson AH (2013) Comment on editorial; best research for Low income countries. Asia Pacific J Med Toxicol 2(2):76

Gannage-Yared MH, Chemali R, Yaacoub N, Halaby G (2000) Hypovitaminosis D in a sunny country: relation to lifestyle and bone markers. J Bone Miner Res 15(9):1856-1862, doi:10.1359/jbmr.2000.15.9.1856

Glazier R, Fry J, Badley E (2001) Arthritis and rheumatism are neglected health priorities: a bibliometric study. J Rheumatol 28(4):706-711

Hofman K, Ryce A, Prudhomme W, Kotzin S (2006) Reporting of noncommunicable disease research in low- and middle-income countries: a pilot bibliometric analysis. J Med Libr Assoc 94(4):415-420

Huber JT, Gullion JS (2003) Complementary and alternative medicine as represented in the HIV/AIDS body of knowledge: a bibliometric analysis. Med Ref Serv Q 22(3):23-32, doi:10.1300/J115v22n03_03

IOF (2011a) Abstracts of the IOF Regionals, 1st Middle-East and Africa Osteoporosis Meeting. October 19-22, 2011. Dubai, United Arab Emirates. Osteoporos Int 22(Suppl 5):S677-S761, doi:10.1007/s00198-011-1746-3

IOF (2011b) The middle east \& Africa Regional Audit. Epidemiology, costs \& burden of osteoporosis in 2011. http://www.iofbonehealth.org/sites/default/ 
files/PDFs/Audit\%20Middle\%20East_Africa/ME_audit-executive_summary.pdf. Accessed August 82014

IOF (2012) Abstracts of the IOF Regionals, 2nd Middle East \& Africa Osteoporosis Meeting, 6th Pan Arab Osteoporosis Congress PAOC'6. September 27October 1, 2012. Dead Sea, Jordan. Osteoporos Int 23(Suppl 6):S655-S700, doi:10.1007/s00198-012-2087-6

Kanis JA, WHO Study Group (1994) Assessment of fracture risk and its application to screening for postmenopausal osteoporosis: synopsis of a WHO report. Osteoporos Int 4(6):368-381, doi:10.1007/BF01622200

Maalouf G, Gannage-Yared MH, Ezzedine J, Larijani B, Badawi S, Rached A, Zakroui L, Masri B, Azar E, Saba E, Nammari R, Adib G, Abou Samra H, Alrawi Z, Salman S, El Muntasser K, Tarseen R, El Kharousi W, Al-Lamki M, Alothman AN, Almarzook N, El Dessouki M, Sulaimani R, Saleh J, Suhaili AR, Khan A, Delmas P, Seeman E (2007) Middle East and North Africa consensus on osteoporosis. J Musculoskelet Neuronal Interact 7(2):131-143

Maese Manzano J (2009) A bibliometric approach to the Spanish scientific production on rheumatology during the 1997-2006 period. Reumatol Clin 5 (5):197-208, doi:10.1016/j.reuma.2008.11.019

Moayyeri A, Soltani A, Larijani B, Naghavi M, Alaeddini F, Abolhassani F (2006) Epidemiology of hip fracture in Iran: results from the Iranian multicenter study on accidental injuries. Osteoporos Int 17(8):1252-1257, doi:10.1007/s00198-006-0105-2

$\mathrm{NIH}$ Consensus Development Panel on Osteoporosis Prevention D, and Therapy (2001) Osteoporosis prevention, diagnosis, and therapy. JAMA 285(6):785-795

Rashidi A, Rahimi B, Delirrad M (2013) Bibliometric analysis of parasitological research in iran and Turkey: a comparative study. Iran J Parasitol 8(2):313-322

Roux C, Wyman A, Hooven FH, Gehlbach SH, Adachi JD, Chapurlat RD, Compston JE, Cooper C, Diez-Perez A, Greenspan SL, Lacroix AZ, Netelenbos JC, Pfeilschifter J, Rossini M, Saag KG, Sambrook PN, Silverman S, Siris ES, Watts NB, Boonen S (2012) Burden of non-hip, non-vertebral fractures on quality of life in postmenopausal women: the Global Longitudinal study of Osteoporosis in Women (GLOW). Osteoporos Int 23(12):2863-2871, doi:10.1007/s00198-012-1935-8

Sakati NO, Nyhan WL (1983) Congenital cutis laxa and osteoporosis. Am J Dis Child 137(5):452-454, doi:10.1001/archpedi.1983.02140310034008

Schreiber M (2013) How relevant is the predictive power of the h-index? A case study of the time-dependent Hirsch index. Journal of Informetrics 7(2):325-329, http://dx.doi.org/10.1016/j.joi.2013.01.001

Shahnazari B, Keshtkar A, Soltani A, Aghamaleki A, Mansour A, Matin B, Saghafi S, Dini M, Khashayar P, Larijani B (2013) Estimating the avoidable burden of certain modifiable risk factors in osteoporotic hip fracture using Generalized Impact Fraction (GIF) model in Iran. J Diabetes Metab Disord 12(1):10, doi:10.1186/2251-6581-12-10

Smith D (2012) Impact factors, scientometrics and the history of citation-based research. Scientometrics 92(2):419-427, doi:10.1007/s11192-012-0685-x

Smith DR (2008) Citation analysis and impact factor trends of 5 core journals in occupational medicine, 1985-2006. Arch Environ Occup Health 63(3):114-122, doi:10.3200/aeoh.63.3.114-122

Smith DR (2010a) Identifying a set of 'core' journals in occupational health, Part 1: lists proposed by others. Arch Environ Occup Health 65(2):106-110, doi:10.1080/19338241003730945

Smith DR (2010b) Identifying a set of 'core'journals in occupational health, part 2: lists derived by bibliometric techniques. Arch Environ Occup Health 65 (3):173-175, Doi:10.1080/19338241003730952

Soveid M, Serati AR, Masoompoor M (2005) Incidence of hip fracture in Shiraz, Iran. Osteoporos Int 16(11):1412-1416, doi:10.1007/s00198-005-1854-Z

Sweileh WM, Al-Jabi SW, Zyoud SH, Sawalha AF (2014a) Bronchial asthma and chronic obstructive pulmonary disease: research activity in Arab countries. Multidiscip Respir Med 9(1):38, doi:10.1186/2049-6958-9-38

Sweileh WM, Zyoud SH, Al-Jabi SW, Sawalha AF (2014b) Assessing urology and nephrology research activity in Arab countries using ISI web of science bibliometric database. BMC Res Notes 7:258, doi:10.1186/1756-0500-7-258

Sweileh WM, Zyoud SH, Al-Jabi SW, Sawalha AF (2014c) Bibliometric analysis of diabetes mellitus research output from Middle Eastern Arab countries during the period (1996-2012). Scientometrics, Article in Press. doi:10.1007/s11192-014-1361-0

Sweileh WM, Zyoud SH, Al-Jabi SW, Sawalha AF (2014d) Quantity and quality of obesity-related research in Arab countries: assessment and comparative analysis. Health Res Policy Syst 12(1):33, doi:10.1186/1478-4505-12-33

Sweileh WM, Zyoud SH, Al-Khalil S, Al-Jabi SW, Sawalha AF (2014e) Assessing the Scientific Research Productivity of the Palestinian Higher Education
Institutions: A Case Study at An-Najah National University, Palestine. SAGE Open 4(3):1-11, doi:10.1177/2158244014544287

Thomson Reuters (2013) Web of knowledge. http://wokinfo.com/media/pdf/ SSR1103443WoK5-2_web3.pdf. Accessed December 112013

Wei L (1995) Bibliometric study of osteoporosis by Integrating medline CD-ROM with foxbase+ 2.10. Chin J Osteoporos, http://en.cnki.com.cn/Article_en/ CJFDTotal-ZGZS502.029.htm. Accessed August 82014

WHO (2011) Global status report on noncommunicable diseases 2010. World Health Organization, Geneva

Zainal H, Zainab AN (2011) Biomedical and health sciences publication productivity from Malaysia. Health Information \& Libraries Journal 28(3):216-225

Zyoud SH, Al-Jabi SW, Sweileh WM (2014a) Worldwide research productivity in the field of electronic cigarette: a bibliometric analysis. BMC Public Health 14:667, doi:10.1186/1471-2458-14-667

Zyoud SH, Al-Jabi SW, Sweileh WM (2014b) Worldwide research productivity of paracetamol (acetaminophen) poisoning: a bibliometric analysis (2003-2012). Hum Exp Toxicol, Article in Press. doi:10.1177/0960327114531993

Zyoud SH, Al-Jabi SW, Sweileh WM, Awang R (2014c) Assessing the scientific research productivity of a leading toxicology journal: a case study of human \& experimental toxicology from 2003 to 2012. SAGE Open Medicine 2:2050312114523424, doi:10.1177/2050312114523424

Zyoud SH, Al-Jabi SW, Sweileh WM, Awang R (2014d) A bibliometric analysis of research productivity of Malaysian publications in leading toxicology journals during a 10-year period (2003-2012). Hum Exp Toxicol, Article in Press. doi:10.1177/0960327113514101

Zyoud SH, Al-Jabi SW, Sweileh WM, Awang R (2014e) A bibliometric analysis of toxicology research productivity in Middle Eastern Arab countries during a 10-year period (2003-2012). Health Res Policy Syst 12(1):4, doi:10.1186/1478-4505-12-4

Zyoud SH, Al-Jabi SW, Sweileh WM, Awang R (2014f) A Scopus-based examination of tobacco use publications in Middle Eastern Arab countries during the period 2003-2012. Harm Reduct J 11:14, doi:10.1186/1477-7517-11-14

\section{doi:10.1186/2193-1801-3-427}

Cite this article as: Sweileh et al:: Osteoporosis is a neglected health priority in Arab World: a comparative bibliometric analysis. SpringerPlus 2014 3:427.

\section{Submit your manuscript to a SpringerOpen ${ }^{\odot}$ journal and benefit from:}

- Convenient online submission

- Rigorous peer review

- Immediate publication on acceptance

- Open access: articles freely available online

- High visibility within the field

- Retaining the copyright to your article

Submit your next manuscript at $\gg$ springeropen.com 